\title{
Influence of Solute and Hydrogen Ion Concentration on the Water Relations of some Xerophilic Fungi
}

\author{
By J. I. PITT AND AILSA D. HOCKING \\ CSIRO Division of Food Research, North Ryde, N.S.W., 2113, Australia
}

(Received 21 September 1976; revised 4 February 1977)

\begin{abstract}
SUMMARY
Germination and growth of six xerophilic fungi, Aspergillus favus, Aspergillus ochraceus, Eurotium chevalieri, Chrysosporium fastidium, Wallemia sebi and Xeromyces bisporus were examined on media of a wide range of water activities $\left(a_{\mathrm{w}}\right)$. The influence of three solutes, $\mathrm{NaCl}$, glycerol and a glucose/fructose mixture, was studied at $\mathrm{pH} 4.0$ and $\mathrm{pH} 6.5$ using a plate-slide technique. Germination times and growth rates were affected by solute type, but the influence of $\mathrm{pH}$ was less marked. Except for Wallemia sebi, the fungi grew most strongly on glucose/fructose and were partially or completely inhibited by $\mathrm{NaCl}$. The results showed that a universal isolation medium for xerophilic fungi could be based on glycerol or glucose/ fructose but not on $\mathrm{NaCl}$ as $a_{\mathrm{w}}$-limiting solute.
\end{abstract}

\section{INTRODUCTION}

The growth of fungi under conditions where water availability is a limiting factor is controlled primarily by the water activity $\left(a_{\mathrm{w}}\right)$ (Scott, 1957). Although other factors such as $\mathrm{pH}$ of the medium and the solutes present are also known to be influential, available data are fragmentary (Pitt, 1975). The present series of experiments was designed to compare the effect of solute and $\mathrm{pH}$ on the germination and growth of several diverse xerophilic fungi.

Pitt (I975) pointed out the need for a medium universally suitable for the isolation of xerophilic fungi from foods and other commodities. This study was designed in part to aid development of such a medium.

A novel procedure was used for studying the germination and growth of the xerophilic fungi. Richter \& Amsterdam (1972) reported that polystyrene plate-slides (Petrislides, manufactured by Millipore Corporation) were well suited to the observation of growing fungal colonies. Using media of known $a_{\mathrm{w}}$ in the Petrislides, their method was adapted to the study of germination and growth rates of xerophiles.

\section{METHODS}

Fungi. Six xerophilic fungal isolates were studied: Aspergillus flavus Link ex Fr. FRR I449, from contaminated milk powder, 1973; Aspergillus ochraceus Wilhelm FRR 1588, isolated by M. D. Connole from cattle feed, 1974; Chrysosporium fastidium Pitt, type isolate, FRR77, from prunes, I964; Eurotium chevalieri Mangin FRR I3 I I, from prunes, 1962; Wallemia sebi (Fries) v. ArX FRRI473, from bread; and Xeromyces bisporus Fraser [= Monascus bisporus (Fraser) v. Arx] FRRI522, from spoiled licorice, I973. FRR denotes the culture collection of the CSIRO Division of Food Research, North Ryde, N.S.W., Australia.

Media. The basal medium was $0.67 \%$ Yeast Nitrogen Base (Difco) plus $2 \%$ glucose and $2 \%$ agar (all $\mathrm{w} / \mathrm{v}$ ). For one series of experiments this was buffered to about $\mathrm{pH} 4.0$ with 
$0.59 \%$ succinic acid and $0.125 \% \mathrm{NaOH}$; for the second to about $\mathrm{pH} 6.5$ with $0.4 \%$ $\mathrm{K}_{2} \mathrm{HPO}_{4}$ (all w/v). The two $\mathrm{pH}$ values were chosen as representing values likely to be encountered in foods of interest and suitable for use in making isolation media.

Media of various water activities were prepared by adding $\mathrm{NaCl}$ or glycerol or a mixture of equal weights of glucose and fructose. Analytical grade chemicals were used throughout. Twelve media were prepared which contained $\mathrm{NaCl}$ as controlling solute, the appropriate concentrations being calculated from the data of Robinson \& Stokes (I955). Water activities ranged from 0.997 to 0.753 . From the formulae of Norrish (1966), I6 glucose/fructose and I4 glycerol media were prepared with $a_{\mathrm{w}}$ values ranging from 0.997 to 0.600 and 0.997 to 0.667 , respectively. As the addition of high concentrations of solutes produced appreciable $\mathrm{pH}$ changes, all media were finally adjusted to $\mathrm{pH} 4.0 \pm 0 . \mathrm{I}$ or $6.5 \pm 0 . \mathrm{I}$, as required, by adding small amounts of $10 \% \mathrm{NaOH}$ or $10 \% \mathrm{HCl}$ (both $\mathrm{w} / \mathrm{v}$ ) just before use. Media of $\mathrm{pH}$ 6.5 and $a_{\mathrm{w}}$ greater than 0.92 were sterilized by autoclaving and the remainder by steam at $100{ }^{\circ} \mathrm{C}$.

Actual $a_{\mathrm{w}}$ values for media of $0.94 a_{\mathrm{w}}$ and below were checked with a Sina-Scope instrument (Sina, Zurich, Switzerland). Corrected values, which rarely varied by more than 0.0 $a_{\mathrm{w}}$ from those calculated, have been used below.

Cultivation. Petrislides (Millipore) containing $2 \mathrm{ml}$ medium were used for growth and examination of the fungi. Each inoculum was a needlepoint of mature spores, placed at the centre of the chamber: if necessary inoculation was carried out by holding the Petrislide inverted to minimize scattering of the spore inculum.

To minimize water transfer to or from the media, inoculated Petrislides were stacked in polyethylene food storage boxes containing dishes of appropriate saturated salt solutions (Robinson \& Stokes, I955). Incubation was at $25^{\circ} \mathrm{C}$ for a maximum period of 100 days.

Examination. To observe germination, Petrislides were examined regularly (initially twice daily, ultimately weekly) by transmitted light microscopy at $100 \times$ magnification. The criterion for germination was the observation of a significant number of germ tubes of length equal to the diameter of the spores examined. Colony diameters were measured at intervals (daily to weekly), initially by an eyepiece micrometer and subsequently by stage verniers. From these data radial growth rates, expressed as $\mu \mathrm{m} \mathrm{h}^{-1}$, were calculated for each time increment. For the period over which growth was approximately linear (Brancato \& Golding, I953), a mean radial growth rate was calculated for each fungus and set of conditions. Early exponential growth (Trinci, I97I) and late suboptimal growth were not included.

\section{RESULTS}

\section{Germination time}

Representative data for germination times are shown in Fig. I, in which log reciprocal germination time is plotted against $a_{\mathrm{w}}$, a technique first used by Snow (1949). Data for four fungi are shown: although lower $a_{\mathrm{w}}$ limits differed somewhat, Aspergillus ochraceus behaved similarly to A. flavus, and Wallemia sebi to Eurotium chevalieri.

Germination of $A$. flavus and $A$. ochraceus was little affected by $\mathrm{pH}$ or solute. For the other fungi, glucose and glycerol were equally favourable substrates, except that Xeromyces bisporus was somewhat intolerant of glycerol at low $a_{\mathrm{w}}$. However, $\mathrm{NaCl}$ caused marked inhibition of $E$. chevalieri at $a_{\mathrm{w}}$ below 0.90 and of Chrysosporium fastidium at $a_{\mathrm{w}}$ below 0.98 . At $\mathrm{pH} 6.5, X$. bisporus failed to germinate at any $a_{\mathrm{w}}$ in the presence of $\mathrm{NaCl}$.

The relationship between germination time and $a_{\mathrm{w}}$ varied widely. Germination times for A. flavus and A. ochraceus were shortest at the highest $a_{\mathrm{w}}$ used (0.997), while X. bisporus and 


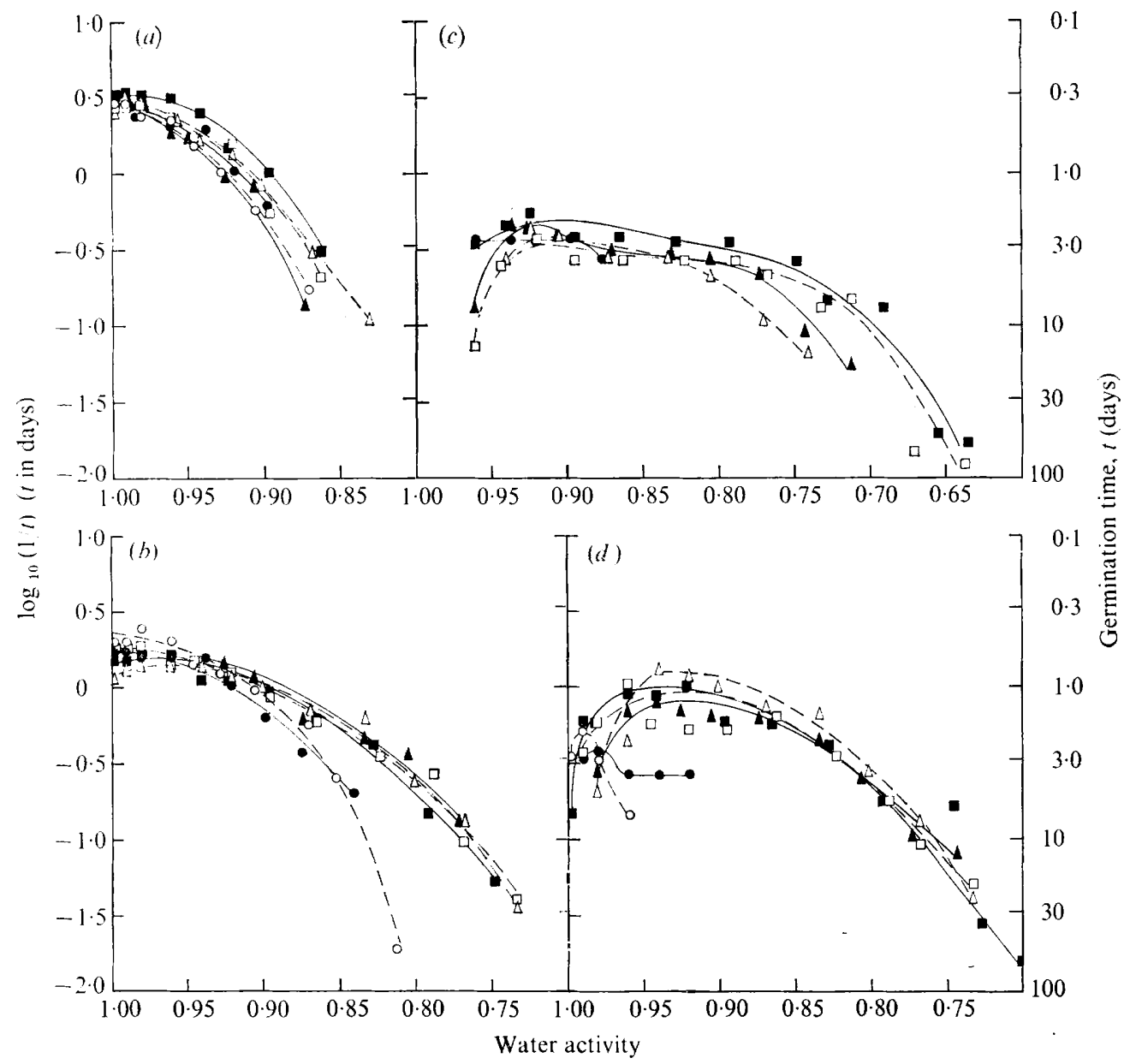

Fig. I. Effect of $a_{\mathrm{w}}$ and solute on the time taken $(t)$ for germination of spores of four xerophilic fungi: (a) Aspergillus flavus; (b) Eurotium chevalieri; (c) Xeromyces bisporus; (d) Chrysosporium

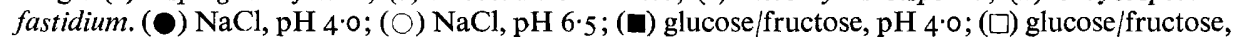
pH 6.5; (ム) glycerol, $\mathrm{pH} 4 \cdot 0 ;(\triangle)$ glycerol, $\mathrm{pH} 6 \cdot 5$.

Table I. Minimum $a_{\mathrm{w}}$ for germination of Aspergillus ochraceus and Wallemia sebi

\begin{tabular}{|c|c|c|c|c|c|}
\hline \multirow[b]{2}{*}{ Solute } & \multirow[b]{2}{*}{$\mathrm{pH}$} & \multicolumn{2}{|c|}{ A. ochraceus } & \multicolumn{2}{|c|}{$W$. sebi } \\
\hline & & Minimum $a_{\mathrm{w}}$ & $\begin{array}{l}\text { Germination } \\
\text { time (days) }\end{array}$ & Minimum $a_{\mathrm{w}}$ & $\begin{array}{l}\text { Germination } \\
\text { time (days) }\end{array}$ \\
\hline $\mathrm{NaCl}$ & $\begin{array}{l}4.0 \\
6.5\end{array}$ & $\begin{array}{l}0.839 \\
0.805\end{array}$ & $\begin{array}{l}6 \cdot 0 \\
69\end{array}$ & $\begin{array}{l}0.805 \\
0.751\end{array}$ & $\underset{12}{5 \cdot 8}$ \\
\hline Glucose/fructose & $\begin{array}{l}4.0 \\
6.5\end{array}$ & $\begin{array}{l}0.792 \\
0.787\end{array}$ & $\begin{array}{l}\text { I2 } \\
2 \mathrm{I}\end{array}$ & $\begin{array}{l}0.69 \mathrm{r} \\
0.7 \mathrm{II}\end{array}$ & $\begin{array}{l}38 \\
42\end{array}$ \\
\hline Glycerol & $\begin{array}{l}4.0 \\
6.5\end{array}$ & $\begin{array}{l}0.806 \\
0.800 *\end{array}$ & $\begin{array}{l}8 \cdot 3 \\
7 \cdot 5\end{array}$ & $\begin{array}{l}0.806 \\
0.700 *\end{array}$ & $\begin{array}{l}4 \cdot 8 \\
25\end{array}$ \\
\hline
\end{tabular}

* Nominal $a_{\mathrm{W}}$ of medium in the absence of Sina-Scope data. 


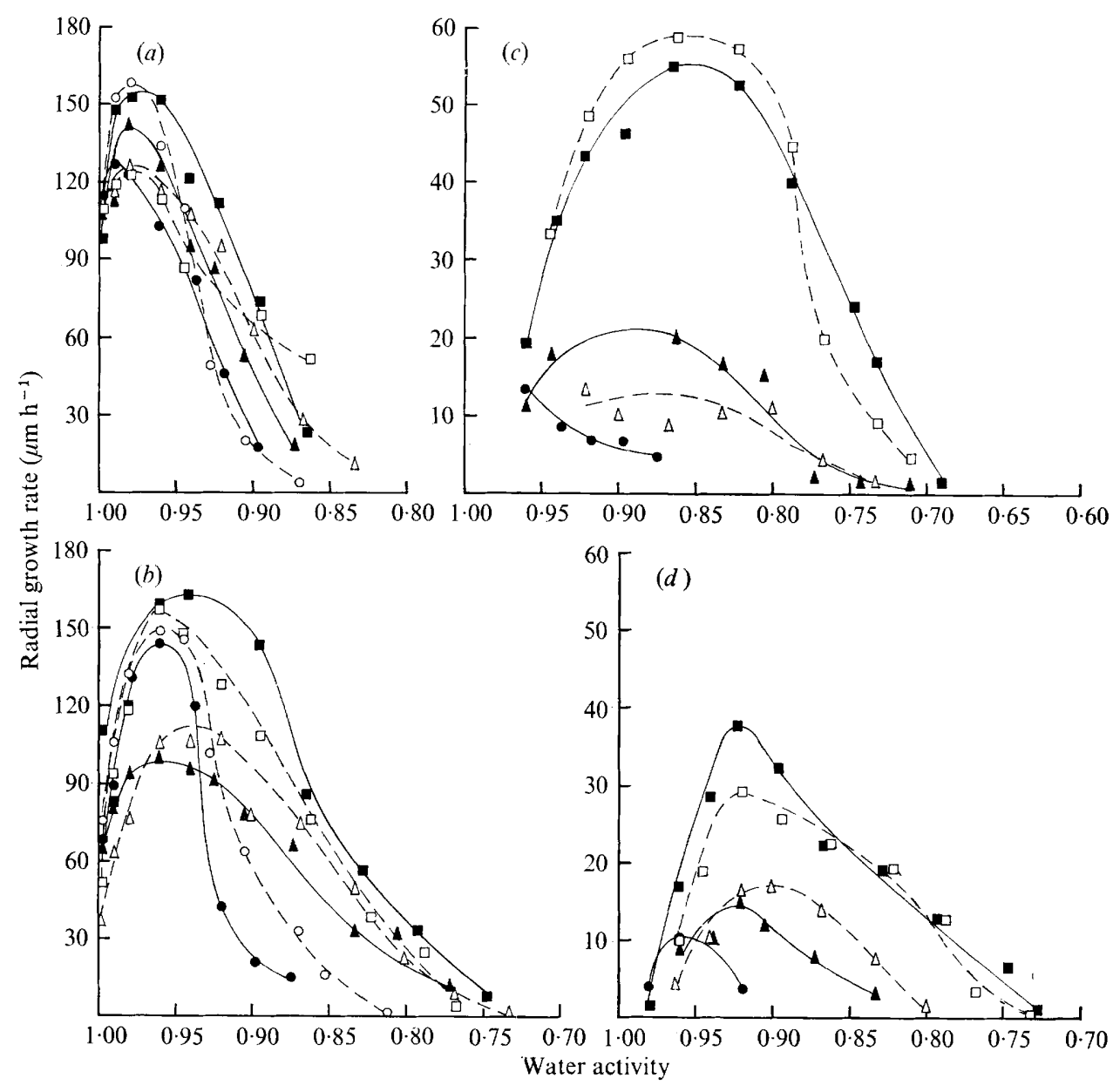

Fig. 2. Effect of $a_{\mathrm{W}}$ and solute on the radial growth rate of four xerophilic fungi: (a) Aspergillus flavus; (b) Eurotium chevalieri; (c) Xeromyces bisporus; (d) Chrysosporium fastidium. (0) $\mathrm{NaCl}$,

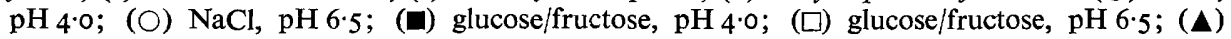
glycerol, $\mathrm{pH} 4 \cdot 0 ;(\triangle)$ glycerol, $\mathrm{pH} 6 \cdot 5$.

C. fastidium germinated most rapidly at much lower $a_{\mathrm{w}}$ values. Xeromyces bisporus failed to germinate above $0.96 a_{\mathrm{w}}$, and germination times remained almost constant over the entire range of 0.94 to $0.80 a_{\mathrm{w}}$.

\section{Minimum $a_{\mathrm{w}}$ for germination}

At high $a_{\mathrm{w}}$ inhibitory effects of $\mathrm{pH}$ or solute usually resulted in extended germination times, but at lower $a_{\mathrm{w}}$ complete inhibition often occurred. The minimum $a_{\mathrm{w}}$ for germination therefore varied widely, as illustrated in Table I and Fig. I. In media containing $\mathrm{NaCl}$, C. fastidium failed to germinate below $0.92 a_{\mathrm{w}}$, but did germinate at $0.7 a_{\mathrm{w}}$ or below in the other systems. The contrast between $\mathrm{NaCl}$ and the other solutes was even more marked for $X$. bisporus. The other fungi were much less affected, although $W$. sebi was relatively intolerant of $\mathrm{pH} 4$ in both glycerol and $\mathrm{NaCl}$. 


\section{Colony growth rates}

Mean radial growth rates for the same four fungi as in Fig. I are shown in Fig. 2: curves for $A$. ochraceus were qualitatively similar to those for $A$. flavus, while growth of $W$. sebi was very slow under all conditions.

The effects of solute and $\mathrm{pH}$ on growth were generally similar to those on germination. Aspergillus flavus showed the least variation in response. Even so, at the optimum $a_{\mathrm{w}}$ for growth $(0.98)$, the radial growth rate on glycerol at $\mathrm{pH} 6.5$ was less than $80 \%$ of that on $\mathrm{NaCl}$ at $\mathrm{pH} 6.5$ or glucose/fructose at $\mathrm{pH} 4$, while at $0.90 a_{\mathrm{w}}$ the growth rate on $\mathrm{NaCl}$ was little more than $20 \%$ of that in glucose/fructose at either $\mathrm{pH}$.

At the other extreme, $X$. bisporus and $C$. fastidium were markedly intolerant of $\mathrm{NaCl}$. At 0.90 to $0.92 a_{\mathrm{w}}$ and $\mathrm{pH} 4.0$, the growth rate was only $10 \%$ of that in glucose/fructose. As noted above, $X$. bisporus failed to germinate in $\mathrm{NaCl}$ at $\mathrm{pH} 6.5 ; C$. fastidium was able to germinate under these conditions, but failed to grow beyond malformed germ tubes.

Unlike the other fungi, $W$. sebi grew best at $\mathrm{pH} 6.5$, and grew more rapidly in $\mathrm{NaCl}$ than in the other solutes at this $\mathrm{pH}$.

\section{Minimum $a_{\mathrm{w}}$ for growth}

Even under unfavourable conditions, germination was usually followed by growth, although when germination required several weeks, growth was sometimes slow and nonlinear during the experiment.

\section{DISCUSSION}

The plate-slide technique proved to be satisfactory for water relations studies. As the Petrislides acted as a barrier between the controlling solution and the medium, undesirable changes in $a_{\mathrm{w}}$ due to water generated by growth might occur. However, measurements made with the Sina-Scope at the conclusion of the experiment indicated that such changes were minor. Errors due to water loss during examination under the microscope, an obvious problem with the technique of Pitt \& Christian (1968), were effectively reduced by the plateslide technique. Moreover, ease and clarity of microscopic inspection were improved.

Based on one series of experiments with a single fungus, Eurotium amstelodami Mangin, Scott (1957) postulated that the optimum $a_{\mathrm{w}}$ for growth of xerophilic fungi was independent of the predominant solute in the medium. His hypothesis appears to have been generally accepted but with little further experimental evidence to support it. In the main our data support his view. With the exception of growth in $\mathrm{NaCl}$ at $\mathrm{pH} 4 \cdot 0, a_{\mathrm{w}}$ optima appeared to vary no more than 0.02 under the conditions examined.

Scott (I957) also noted that the absolute rates of growth over a range of $a_{\mathrm{w}}$ depend on the nature of the solute. The data reported here amplify his statement. The less-specialized fungi, the Aspergillus species, were little affected by solute type at either $\mathrm{pH}$ over the entire range of $a_{\mathrm{w}}$ at which germination and growth occurred. The more highly adapted fungi, Xeromyces bisporus and Chrysosporium fastidium, were markedly intolerant of solutes other than glucose/fructose.

Wallemia sebi was reported by Frank \& Hess (194I) to have an obligate requirement for $\mathrm{NaCl}$, i.e. to be a halophile. However, Vaisey (I954) showed it to be equally capable of growth at low $a_{\mathrm{w}}$ in other solutes including glucose. Data in Table I and other results (not shown) indicate $W$. sebi grows best at neutral $\mathrm{pH}$ but has no requirement for $\mathrm{NaCl}$ as a solute. Because neither $W$. sebi nor any other fungus has been shown to require $\mathrm{NaCl}$ for growth at low $a_{\mathrm{w}}$, the term halophile is properly restricted to bacteria. 
Schmiedeknecht (1960) suggested that xerophiles could be classified by their optimum $a_{\mathrm{w}}$ for growth. Certainly, it is to be expected that the lower the optimum $a_{\mathrm{w}}$, the more xerophilic a fungus would be. On this basis, the fungi examined here can be placed in order: Aspergillus flavus (optimum $\left.a_{\mathrm{w}} 0.98\right)$, A. ochraceus (0.98 to 0.95), Eurotium chevalieri (0.96 to 0.94 ), Wallemia sebi (0.94), Chrysosporium fastidium (0.92) and Xeromyces bisporus (0.86). There is a strong correlation (using $\mathrm{I}-a_{\mathrm{w}}$ as variates, $r^{2}=0.826$ ) between these optima and the minimum $a_{\mathrm{w}}$ for germination in the most favourable solute.

The findings reported above have important implications for the development of isolation media for xerophiles. The use of media containing high concentrations of $\mathrm{NaCl}$, first suggested by Christensen (1946) and widely used since, is clearly unsatisfactory. Although the other fungi grew well, C. fastidium and $X$. bisporus were intolerant of $\mathrm{NaCl}$. The glucose/ fructose mixture provided favourable growth conditions for all of the fungi studied. However, the concentrations of the sugars required to produce 0.90 or $0.85 a_{\mathrm{w}}$ make this medium difficult to handle, because of high viscosity, and relatively expensive. Glycerol, an ideal solute in terms of ease of use and cheapness, is a possible alternative. At $0.90 a_{\mathrm{w}}$ all of the fungi examined grew reasonably well in this medium, at $30 \%$ or more of the maximum rates achieved. At $0.85 a_{\mathrm{w}}, W$. sebi grew in the presence of glycerol only at $\mathrm{pH} 6.5$, so a universal medium based on glycerol would need to be of near neutral $\mathrm{pH}$.

\section{REFERENCES}

Brancato, F. P. \& Golding, N. S. (1953). The diameter of the mold colony as a reliable measure of growth. Mycologia 45, 848-864.

Christensen, C. M. (1946). The quantitative determination of molds in flour. Cereal Chemistry 23, 322-329.

Frank, M. \& Hess, E. (194I). Studies on salt fish. VI. Halophilic brown molds of the genus Sporendonema emend. Ciferri et Redaelli. Journal of the Fisheries Research Board of Canada 5, 287-292.

NorRISH, R. S. (1966). An equation for the activity coefficients and equilibrium relative humidities of water in confectionery syrups. Journal of Food Technology $\mathbf{1}, 25-39$.

PITT, J. I. (1975). Xerophilic fungi and the spoilage of foods of plant origin. In Water Relations of Foods, pp. 273-307. Edited by R. B. Duckworth. London: Academic Press.

PitT, J. I. \& Christian, J. H. B. (I968). Water relations of xerophilic fungi isolated from prunes. Applied Microbiology $\mathrm{x6}, \mathrm{I} 853-1858$.

Richter, M. W. \& AmSTERdam, D. (1972). Plate-slide for the culture and morphological observation of fungi. Applied Microbiology 24, 667-668.

Robinson, R. A. \& Stokes, R. H. (1955). Electrolyte Solutions. New York and London: Academic Press.

SCHMiedeKNeCht, M. (I970). Feuchtigkeit als standort Faktor für mikroskopische Pilze. Zeitschrift für Pilzkunde 25, 69-77.

Scotr, W. J. (1957). Water relations of food spoilage microorganisms. Advances in Food Research 7, 83-127.

SNOw, D. (1949). The germination of mould spores at controlled humidities. Annals of Applied Biology 36, I-I3.

TrincI, A. J. P. (197I). Exponential growth of the germ tubes of fungal spores. Journal of General Microbiology $67,345^{-348 .}$

VAISEY, E. B. (1954). Osmophilism of Sporendonema epizoum. Journal of the Fisheries Research Board of Canada II, 901-903. 